\title{
Co-production of hydrogen
} and ethanol from glucose in Escherichia coli by activation of pentose-phosphate pathway through deletion of phosphoglucose isomerase ( $p g i)$ and overexpression of glucose-6-phosphate dehydrogenase ( $z w f)$
and 6-phosphogluconate dehydrogenase ( $g n d)$

Balaji Sundara Sekar ${ }^{\dagger}$, Eunhee Seol ${ }^{\dagger}$ and Sunghoon Park ${ }^{*}$

\begin{abstract}
Background: Biologically, hydrogen $\left(\mathrm{H}_{2}\right)$ can be produced through dark fermentation and photofermentation. Dark

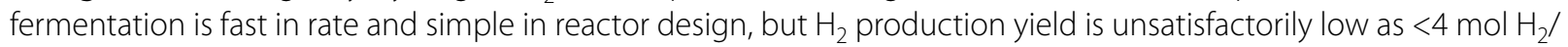
mol glucose. To address this challenge, simultaneous production of $\mathrm{H}_{2}$ and ethanol has been suggested. Co-production of ethanol and $\mathrm{H}_{2}$ requires enhanced formation of $\mathrm{NAD}(\mathrm{P}) \mathrm{H}$ during catabolism of glucose, which can be accomplished by diversion of glycolytic flux from the Embden-Meyerhof-Parnas (EMP) pathway to the pentose-phosphate (PP) pathway in Escherichia coli. However, the disruption of pgi (phosphoglucose isomerase) for complete diversion of carbon flux to the PP pathway made E. coli unable to grow on glucose under anaerobic condition.

Results: Here, we demonstrate that, when glucose-6-phosphate dehydrogenase (Zwf) and 6-phosphogluconate dehydrogenase (Gnd), two major enzymes of the PP pathway, are homologously overexpressed, E. coli $\triangle p g i$ can recover its anaerobic growth capability on glucose. Further, with additional deletions of $\triangle h y c A, \triangle h y a A B, \triangle h y b B C$, $\triangle l d h A$, and $\triangle$ frd $A B$, the recombinant $\triangle$ pgi mutant could produce $1.69 \mathrm{~mol} \mathrm{H}_{2}$ and $1.50 \mathrm{~mol}$ ethanol from $1 \mathrm{~mol}$ glucose. However, acetate was produced at $0.18 \mathrm{~mol} \mathrm{~mol}^{-1}$ glucose, indicating that some carbon is metabolized through the Entner-Doudoroff (ED) pathway. To further improve the flux via the PP pathway, heterologous zwf and gnd from Leuconostoc mesenteroides and Gluconobacter oxydans, respectively, which are less inhibited by NADPH, were overexpressed. The new recombinant produced more ethanol at $1.62 \mathrm{~mol} \mathrm{~mol}^{-1}$ glucose along with $1.74 \mathrm{~mol} \mathrm{H}_{2} \mathrm{~mol}^{-1}$ glucose, which are close to the theoretically maximal yields, $1.67 \mathrm{~mol} \mathrm{~mol}^{-1}$ each for ethanol and $\mathrm{H}_{2}$. However, the attempt to delete the ED pathway in the $\triangle p g i$ mutant to operate the PP pathway as the sole glycolytic route, was unsuccessful.
\end{abstract}

Conclusions: By deletion of pgi and overexpression of heterologous zwf and gnd in E. coli $\triangle$ hycA $\triangle$ hyaAB $\triangle$ hybBC $\triangle l d h A \triangle f r d A B$, two important biofuels, ethanol and $\mathrm{H}_{2}$, could be successfully co-produced at high yields close to their

\footnotetext{
*Correspondence: parksh@pusan.ac.kr

${ }^{\dagger}$ Balaji Sundara Sekar and Eunhee Seol contributed equally to this work Department of Chemical and Biomolecular Engineering, Pusan National University, 2, Busandaehak-ro 63 beon-gil, Geumjeong-gu, Busan 46241, Republic of Korea
} 
theoretical maximums. The strains developed in this study should be applicable for the production of other biofuels and biochemicals, which requires supply of excessive reducing power under anaerobic conditions.

Keywords: Biohydrogen, Co-production of hydrogen and ethanol, Phosphoglucose isomerase deletion, Pentosephosphate pathway, Escherichia coli

\section{Background}

Hydrogen $\left(\mathrm{H}_{2}\right)$ is considered as a promising alternative to fossil fuel as it is an efficient energy carrier and produces zero carbon emission. Currently, $\mathrm{H}_{2}$ is produced by steam reforming process using natural gas, a non-renewable source. Therefore, as an alternative, biological $\mathrm{H}_{2}$ production by photolysis, photofermentation, or dark fermentation has been studied for decades due to its dependence on renewable energy source. Dark fermentation, owing to its rapidity and simplicity, usually is the preferred approach [1-3], though its theoretical $\mathrm{H}_{2}$ yield is low: typically $<2 \mathrm{~mol} \mathrm{~mol}^{-1}$ glucose for mesophilic bacteria such as Escherichia coli [4] and $<4 \mathrm{~mol} \mathrm{~mol}^{-1}$ glucose for strict anaerobes such as Clostridia, Thermoanaerobacter tengcongensis, Pyrococcus furiosus, and others [5-7]. To improve $\mathrm{H}_{2}$ production yield in E. coli, introduction of heterologous pathways such as ferredoxin- or $\mathrm{NAD}(\mathrm{P}) \mathrm{H}$-dependent $\mathrm{H}_{2}$ production pathways has been attempted. The heterologous pathways, though functional in $E$. coli, have been shown to be highly inefficient and, as such, non-conducive to practical improvements in $\mathrm{H}_{2}$ yield [8]. In the case of strict anaerobes, higher yield, close to $4 \mathrm{~mol} \mathrm{~mol}^{-1}$ glucose, have been reported [9], albeit still not high enough to be commercially interesting. Due to the lack of a genetic tool box and/or the difficulty for gene manipulation, serious pathway engineering in strict anaerobes is yet to be attempted. As alternative means of addressing dark fermentation's low $\mathrm{H}_{2}$ production yield, hybrid processes such as dark plus photofermentation, hythane process (production of $\mathrm{H}_{2}$ in the first stage and methane in the second), etc., have been studied [10-12]. Albeit efficient and feasible on the laboratory scale, these hybrid processes' industrial application is highly challenging due to complicated reactor configurations and/or operation. We have suggested, as an alternative, a simple process by which $\mathrm{H}_{2}$ and ethanol are co-produced in a single bioreactor [13]. Ethanol in fact is a good liquid biofuel, and can easily be separated from gaseous $\mathrm{H}_{2}$. Co-production of ethanol with $\mathrm{H}_{2}$, moreover, can significantly increase the energy recovery of dark fermentation and, thereby, make $\mathrm{H}_{2}$ production from glucose more attractive [14].

Under typical anaerobic conditions, E. coli metabolizes most of the glucose through the EMP pathway, producing $\mathrm{H}_{2}$ at $2 \mathrm{~mol} \mathrm{~mol}^{-1}$ glucose along with ethanol and acetate each at $1 \mathrm{~mol} \mathrm{~mol}^{-1}$ glucose (Fig. 1). Co-production of ethanol with $\mathrm{H}_{2}$ requires the production of ethanol instead of acetate, which entails conversion of the two molecules of acetyl-CoA produced from one molecule of glucose to two molecules of ethanol, without producing acetate. This requires additional $\mathrm{NAD}(\mathrm{P}) \mathrm{H}$ generation during glycolysis. For this purpose, use of a more reduced carbon source than glucose, such as glycerol, has been studied [15] for the production of equimolar $\mathrm{H}_{2}$ and ethanol without acetate. However, with glucose as the carbon source, the theoretical maximum yield of ethanol cannot exceed $1 \mathrm{~mol}$ per mol of glucose, because the EMP pathway generates only 2 mol NADH per mol of glucose. However, if glucose is exclusively metabolized through the PP pathway, $3.67 \mathrm{~mol} \mathrm{NAD(P)H} \mathrm{per} \mathrm{mol} \mathrm{of}$ glucose can be generated, which, in theory, enables coproduction of ethanol and $\mathrm{H}_{2}$, each at $1.67 \mathrm{~mol} \mathrm{~mol}^{-1}$, without acetate [13]. To this end, blockage of the EMP pathway by deletion of phosphoglucose isomerase (Pgi) has been attempted; unfortunately though, the $\Delta p g i$ strain could not grow anaerobically. In response, for coproduction of $\mathrm{H}_{2}$ and ethanol, alternative, phosphofructokinase-1 (PfkA) deletion mutants have been developed and studied (Fig. 1) [14, 16]. The $\Delta p f k A$ strains could grow well after long adaptation to anaerobic conditions [14] and produced significant amounts of $\mathrm{H}_{2}$ and ethanol $\left(\sim 1.8 \mathrm{~mol} \mathrm{H}_{2} \mathrm{~mol}^{-1}\right.$ and $\sim 1.40 \mathrm{~mol}$ ethanol $\mathrm{mol}^{-1}$ ) when Zwf and Gnd, the key enzymes of the PP pathway, were overexpressed. However, due to the active expression of $p f k B$, which encodes for isozyme of PfkA, up to $30 \%$ of the glucose was metabolized through the EMP pathway in the $\triangle p f k A$ strains, thus resulting in substantial acetate production $\left(\sim 0.15 \mathrm{~mol} \mathrm{~mol}^{-1}\right)$ [14].

In the present study, we determined that $\Delta p g i$ mutants can grow anaerobically when Zwf and Gnd are overexpressed. Consequently, we investigated complete blockage of the carbon flux through the EMP pathway and the concomitantly improved co-production of $\mathrm{H}_{2}$ and ethanol. Also, to address the two major disadvantages of Zwf and Gnd of E. coli-their dependence on $\mathrm{NADP}^{+}$as the cofactor and serious inhibition of their activities by $\mathrm{NADPH}$ at the enzyme level-expressions of heterologous Zwf and Gnd from other microorganisms have been studied. We also attempted deletion of the ED pathway for operation of the PP pathway as the sole glycolytic route. Our results demonstrate that $\Delta p g i$ mutants can grow under anaerobic conditions and co-produce $\mathrm{H}_{2}$ and 


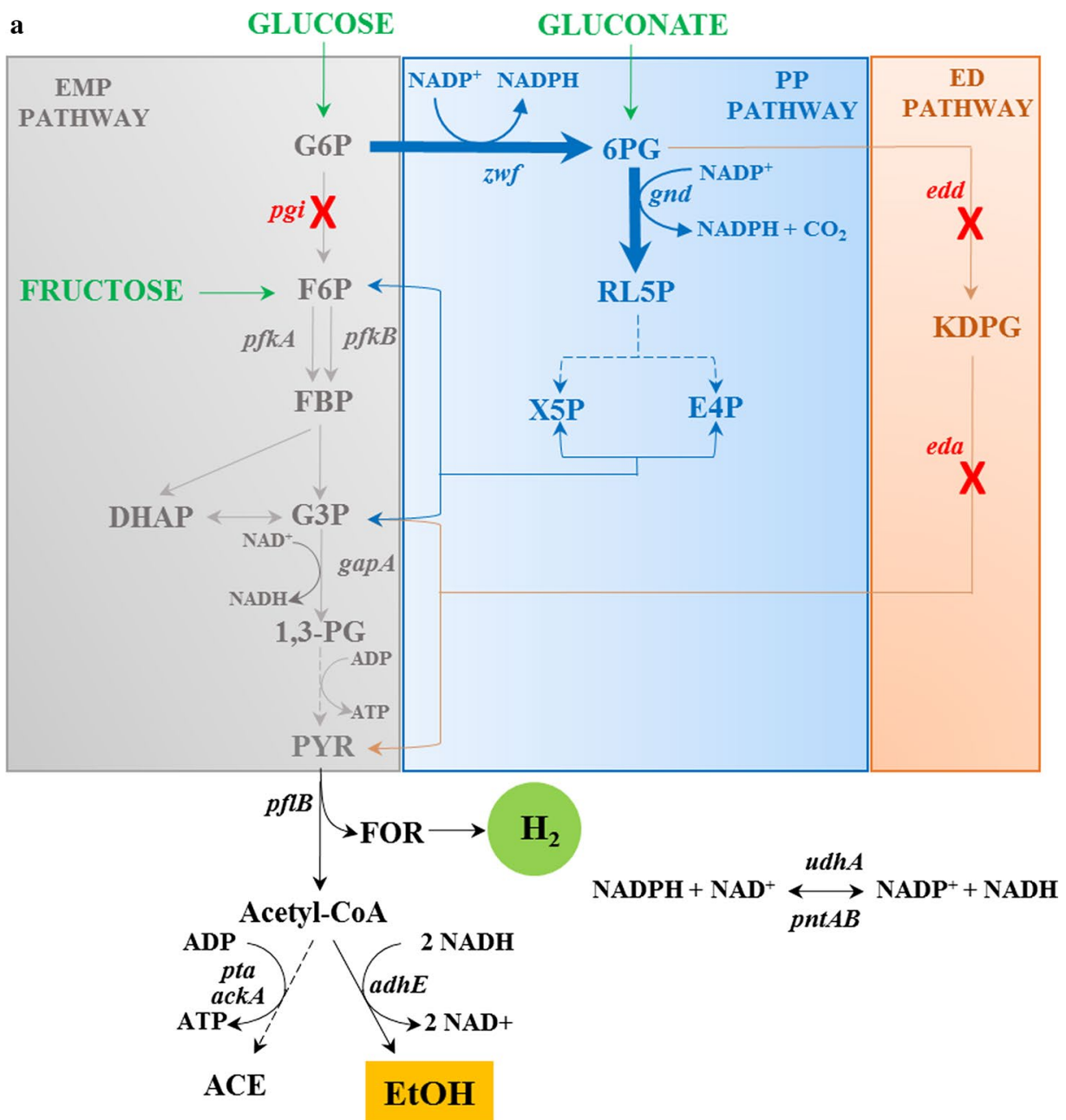

b

EMP pathway 1 Glucose $\rightarrow 2$ pyruvate +2 ATP +2 NADH

1 Glucose $\rightarrow 2 \mathrm{H}_{2}+1 \mathrm{EtOH}+1$ Acetate $+3 \mathrm{ATP}+0 \mathrm{NADH}$

PP pathway 3 Glucose $\rightarrow 5$ pyruvate +5 ATP +11 NAD(P)H

1 Glucose $\rightarrow 1.67 \mathrm{H}_{2}+1.67 \mathrm{EtOH}+1.67 \mathrm{ATP}+0.33 \mathrm{NAD}(\mathrm{P}) \mathrm{H}$

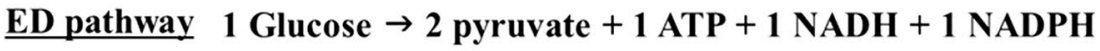

1 Glucose $\rightarrow 2 \mathrm{H}_{2}+1 \mathrm{EtOH}+1$ Acetate +2 ATP +0 NAD(P)H

Fig. 1 a Pathway engineering for promotion of carbon flux through PP pathway. The EMP and ED pathways were disrupted by deleting pgi, edd, and eda (red crosses), and the PP pathway was activated by the overexpression of zwf and gnd (bold blue arrows). b Theoretical carbon and energy balance of EMP, PP (non-cyclic), and ED pathway of base strain (SH5) for co-production of $\mathrm{H}_{2}$ and ethanol. Genes: pgi-phosphoglucose isomerase, pfk — phosphofructokinase, gapA—glyceraldehyde-3-phosphate dehydrogenase, pta — phosphotransacetylase, ackA—acetate kinase, adhE —alcohol dehydrogenase, zWf-glucose-6-phosphate dehydrogenase, gnd-6-phosphogluconate dehydrogenase, edd-Entner-Doudoroff dehydratase, eda —Entner-Doudoroff aldolase, udhA—soluble transhydrogenase, pntAB —-membrane-bound transhydrogenase. Metabolites: G6P—Glucose6-phosphate, F6P_fructose-6-phosphate, FBP_fructose-1,6-bisphosphate, DHAP_dihydroxyacetone phosphate, G3P-glyceraldehyde-3-phosphate, 1,3-PG—1,3-bisphosphoglycerate, PYR - pyruvate, FOR—formate, $\mathrm{H}_{2}$ - hydrogen, AcCoA—acetyl-CoA, ACE—acetate, EtOH—ethanol, 6PG -6-phosphogluconate, RL5P_ribulose-5-phosphate, X5P_xylose-5-phosphate, E4P_erythrose-4-phosphate, KDPG—2-Keto-3-deoxy6-phosphogluconate 
ethanol at near-theoretical yields. Additionally, the data obtained show that the developed strains can be used as an interesting platform when generation of considerable reducing power is needed in anaerobic glucose metabo$\operatorname{lism}[17,18]$.

\section{Methods}

\section{Strains, plasmids, and materials}

The Escherichia coli BW25113 mutant strain (SH5) from our previous study [19] was used as a base strain in this work. Restriction and DNA-modifying enzymes were obtained from New England Bio-Labs (Beverly, MA, USA). The Miniprep and DNA gel extraction kits were purchased from Qiagen (Mannheim, Germany). The primers were synthesized by Macrogen Inc. (Seoul, Korea). The yeast extract (Cat. 212750) and Bacto ${ }^{\mathrm{TM}}$ tryptone (Cat. 211705) were acquired from Difco (BectonDickinson; Franklin Lakes, NJ, USA). Unless indicated otherwise, all of the other chemicals were obtained from Sigma-Aldrich (St. Louis, MO, USA).

\section{Construction of recombinant $E$. coli strains}

For overexpression of $\mathrm{Zwf}$ and/or Gnd, the plasmids pEcZ, pEcG, and pEcZG from our previous study were utilized [14]. Gene deletion was performed using either the $\lambda$-Red recombinase (deletion of $p g i$ ) or pKOV system (deletion of $e d d, u d h A$, and pntAB) [20, 21]. Briefly, for deletion using $\lambda$-Red recombinase, hybrid complementary primers for pgi of E. coli BW25113 and the antibiotic cassette (FRT-kan-FRT) in pKD4, were used. The amplified FRT-kan-FRT cassette was inserted to SH5 harboring pKD46 plasmid by electroporation. The resulting kanamycin-resistant E. coli SH5 containing FRTkan-FRT in the pgi region was isolated using antibiotic resistance screening and PCR with the locus-specific primers. For deletion using pKOV system, recombinant pKOV plasmid was made with PCR-amplified upstream and downstream $500 \mathrm{bp}$ of the target gene. This recombinant plasmid was used to perform double recombination and remove the target gene using sucrose (sacB-dependent) as selection pressure. The heterologous $z w f$ and gnd were codon optimized and synthesized by GenScript (NJ, USA) (Additional file 1: Table S1). All the genes for overexpression were cloned in pDK7 vector and overexpressed under the control of the tac promoter [22]. The list of strains constructed in this study is provided in Table 1.

\section{Culture conditions}

Luria-Bertani broth was used to culture the cells for genetic engineering and culture maintenance work. Production studies were performed in modified M9 medium containing $5.0 \mathrm{~g} \mathrm{~L}^{-1}$ glucose or gluconate, $1.0 \mathrm{~g} \mathrm{~L}^{-1}$ yeast extract, $3.0 \mathrm{~g} \mathrm{~L}^{-1} \mathrm{Na}_{2} \mathrm{HPO}_{4}, 1.5 \mathrm{~g} \mathrm{~L}^{-1} \mathrm{KH}_{2} \mathrm{PO}_{4}$, $0.5 \mathrm{~g} \mathrm{~L}^{-1} \mathrm{NH}_{4} \mathrm{Cl}, 0.25 \mathrm{~g} \mathrm{~L}^{-1} \mathrm{NaCl}, 0.25 \mathrm{~g} \mathrm{~L}^{-1} \mathrm{MgSO}_{4}$, and $0.01 \mathrm{~g} \mathrm{~L}^{-1} \mathrm{CaCl}_{2}$. Kanamycin $\left(50 \mu \mathrm{g} \mathrm{mL}^{-1}\right)$ and chloramphenicol $\left(25 \mu \mathrm{g} \mathrm{mL}^{-1}\right)$ were added to the medium for culturing of the recombinant strains. The medium was also supplemented with $0.2 \mathrm{mg} \mathrm{L}^{-1} \mathrm{NiSO}_{4}, 1.4 \mathrm{mg} \mathrm{L}^{-1}$ $\mathrm{FeSO}_{4}, 0.2 \mathrm{mg} \mathrm{L}^{-1} \mathrm{Na}_{2} \mathrm{SeO}_{3}, 0.2 \mathrm{mg} \mathrm{L}^{-1} \mathrm{Na}_{2} \mathrm{MoO}_{4}$, and $8.8 \mathrm{mg} \mathrm{L}^{-1}$ cysteine $\mathrm{HCl}$ for supporting the synthesis of co-production-related enzymes. The cells were cultured anaerobically with $50 \mathrm{~mL}$ of M9 medium in $165 \mathrm{~mL}$ serum bottles. The serum bottles with the media were flushed with argon for 15 min to create the anoxic condition for fermentation. The cells were cultured at $37{ }^{\circ} \mathrm{C}$ in an orbital shaker rotating at $200 \mathrm{rpm}$. The expressions of Zwf and Gnd were induced by the addition of $0.1 \mathrm{mM}$ isopropyl- $\beta$-D-thiogalactopyranoside (IPTG), unless stated otherwise.

\section{Total RNA isolation and real-time PCR}

The recombinant strains were induced with IPTG and harvested during the late exponential growth phase. RNAprotect reagent (Qiagen Inc., USA) was added to the cell pellets, which were stored at $-80{ }^{\circ} \mathrm{C}$ to prevent RNA degradation. Total RNA was extracted using the Nucleospin ${ }^{\circledR}$ RNA isolation kit (Macherey-Nagel, Germany) and converted to cDNA using the SuperScript III first-strand synthesis system (Invitrogen, USA). The RTPCR primers were designed using Primer Express ${ }^{\circledR}$ software. RT-PCR analysis was performed using the StepOne real-time PCR system (Applied Biosystems, USA). The experiment was conducted in duplicate using the SYBR Green method, and the relative mRNA was quantified by the $\Delta \mathrm{C}_{\mathrm{T}}$ method [23]. rpoD was utilized as the endogenous control.

\section{Determination of enzyme activities}

The enzyme activities of Gnd and Zwf were measured as described in Moritz et al. [24], with slight modifications. Briefly, the enzyme activities were performed in $50 \mathrm{mM}$ Tris- $\mathrm{HCl}(\mathrm{pH} 7.5)$ containing $0.2 \mathrm{mM} \mathrm{NADP}^{+}$, $1 \mathrm{mM} \mathrm{MgCl}{ }_{2}$, and $0.5 \mathrm{mM}$ glucose-6-phosphate or 6-phosphogluconate. The reduction of $\mathrm{NADP}^{+}$was observed at $340 \mathrm{~nm}$. The extinction coefficient $\left(\varepsilon_{340}\right)$ of $6.22 \mathrm{mM}^{-1} \mathrm{~cm}^{-1}$ was used for calculating the amount of NADPH formed in the assay. All measurements were performed at $30^{\circ} \mathrm{C}$.

\section{Analytical methods}

Cell growth was monitored by UV spectrophotometry (Lambda 20, Perkin Elmer, USA) measurement of the optical density $\left(\mathrm{OD}_{600}\right)$ at $600 \mathrm{~nm}$. Gases such as $\mathrm{H}_{2}$ and $\mathrm{CO}_{2}$ were measured by gas chromatography (DS6200 Donam Systems Inc., Seoul, Korea) equipped with a TCD 
Table 1 Strains and plasmids used in this study

\begin{tabular}{|c|c|c|}
\hline & Description & References \\
\hline \multicolumn{3}{|l|}{ Strains } \\
\hline SH5 & BW25113 $\triangle$ hycA $\triangle$ hyaAB $\triangle$ hybBC $\triangle l d h A \triangle$ frd $A B$ & Kim et al. [19] \\
\hline $\mathrm{SH} 5 \Delta p g i$ & $\mathrm{SH} 5 \Delta p g i$ & This study \\
\hline SH5 $\triangle p g i \_Z$ & SH5 $\triangle p g i$ harboring $p E c Z$ & \\
\hline SH5 $\Delta p g i \_Z G$ & SH5 $\triangle$ pgi harboring pEcZG & \\
\hline SH5 $\triangle p g i \_Z G U$ & SH5 $\triangle p$ gi harboring pEcZGU & \\
\hline $\mathrm{SH} 5 \Delta p g i Z_{L} G_{E}$ & SH5 $\Delta$ pgi harboring pLmZ-EcG & \\
\hline $\mathrm{SH} 5 \Delta p g i \_Z_{Z} G_{E}$ & SH5 $\triangle$ pgi harboring pZmZ-EcG & \\
\hline $\mathrm{SH} 5 \Delta$ pgi_Z $Z_{E} G_{C}$ & SH5 $\triangle p$ gi harboring pEcZ-CgG & \\
\hline SH5 $\triangle p g i Z_{L} G_{C}$ & $\mathrm{SH} 5 \Delta p g i$ harboring pLmZ-CgG & \\
\hline $\mathrm{SH} 5 \Delta$ pgi_ZZ $\mathrm{G}_{C}$ & $\mathrm{SH} 5 \Delta p g i$ harboring $\mathrm{pZmZ-CgG}$ & \\
\hline $\mathrm{SH} 5 \Delta p g i Z_{E} G_{G}$ & SH5 $\triangle p$ gi harboring pEcZ-GoG & \\
\hline $\mathrm{SH} 5 \Delta p g i Z_{L} G_{G}$ & SH5 $\Delta p g i$ harboring pLmZ-GoG & \\
\hline $\mathrm{SH} 5 \Delta p g i \_Z_{Z} G_{G}$ & $\mathrm{SH} 5 \Delta$ pgi harboring pZmZ-GoG & \\
\hline $\mathrm{SH} 5 \Delta$ pgi $\Delta$ edd & $\mathrm{SH} 5 \Delta$ pgi $\Delta e d d e d a$ & \\
\hline SH5 $\triangle$ pgi $\Delta e d d \_G$ & $\mathrm{SH} 5 \triangle$ pgi $\triangle$ edd harboring $\mathrm{pECG}$ & \\
\hline 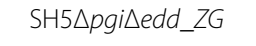 & $\mathrm{SH} 5 \Delta$ pgi $\Delta e d d$ harboring $\mathrm{pEcZG}$ & \\
\hline $\mathrm{SH} 5 \Delta$ pgi $\Delta$ edd_Z $Z_{L} G_{G}$ & $\mathrm{SH} 5 \Delta$ pgi $\Delta$ edd harboring pLmZ-GoG & \\
\hline \multicolumn{3}{|l|}{ Plasmids } \\
\hline pDK7 & Expression vector & Kleiner et al. [22] \\
\hline $\mathrm{pECZ}$ & pDK7 carrying zwf of E. coli BW25113 & Sundara Sekar et al. [14] \\
\hline $\mathrm{pEcZG}$ & pDK7 carrying zwf, gnd of E. coli BW25113 & \\
\hline pEcZGU & pDK7 carrying zwf, gnd, udhA of E. coli BW25113 & This study \\
\hline pLmZ-EcG & pDK7 carrying zwf of L. mesenteroides and gnd of E. coli BW25113 & \\
\hline $\mathrm{pZmZ-EcG}$ & pDK7 carrying zwf of Z. mobilis and gnd of E. coli BW25113 & \\
\hline $\mathrm{pECZ}-\mathrm{CgG}$ & pDK7 carrying zwf of E. coli BW25113 and gnd of C. glutamicum & \\
\hline $\mathrm{pLmZ-CgG}$ & pDK7 carrying zwf of L. mesenteroides and gnd of C. glutamicum & \\
\hline $\mathrm{pZmZ-CgG}$ & pDK7 carrying zwf of Z. mobilis and gnd of C. glutamicum & \\
\hline pEcZ-GoG & pDK7 carrying zwf of E. coli BW25113 and gnd of G. oxydans & \\
\hline pLmZ-GoG & pDK7 carrying zwf of L. mesenteroides and gnd of G. oxydans & \\
\hline pZmZ-GoG & pDK7 carrying zwf of Z. mobilis and gnd of G. oxydans & \\
\hline
\end{tabular}

detector. The stainless steel column of gas chromatography was packed with either Hayesep Q (for $\mathrm{CO}_{2}$ analysis, Alltech Deerfield, IL, USA) or Molecular Sieve 5A (for $\mathrm{H}_{2}$ analysis, Alltech Deerfield, IL, USA). Argon was used as the carrier gas and its flow rate was set at $30 \mathrm{~mL} \mathrm{~min}^{-1}$. The temperature of injector, column oven, and TCD detector was maintained at 90,80 , and $120^{\circ} \mathrm{C}$, respectively, during analysis. Glucose, ethanol, and all of the other metabolites were measured by high-performance liquid chromatography (Agilent Technologies, HP, 1200 series) equipped with a refractive index (RID) and photodiode array (DAD) detectors. The post-fermentation medium was centrifuged and filtered, and samples were eluted through a $300 \mathrm{~mm} \times 7.8 \mathrm{~mm}$ Aminex HPX-87H (Bio-Rad) column at $65^{\circ} \mathrm{C}$ using $2.5 \mathrm{mM} \mathrm{H}_{2} \mathrm{SO}_{4}$. The protein concentrations of the samples used in the enzyme activities were determined by the Bradford method as described previously [25] using bovine serum albumin as the standard.

\section{Results and discussion \\ Growth of $E$. coli mutant lacking pgi under aerobic and anaerobic conditions}

To completely block the carbon flux through the EMP pathway and divert it through the PP pathway, the pgi gene was deleted from the E. coli BW25113 mutant strain (designated as ' $\mathrm{SH} 5$ '), which has several deletions in such enzymes as uptake hydrogenases (hyaAB, $h y b B C$ ), the negative regulator of formate-hydrogen lyase $(h y c A)$, lactate dehydrogenase $(l d h A)$, and fumarate reductase $(\operatorname{rrd} A B)$ [19]. The resulting mutant strain $E$. coli SH5 $\triangle p g i$ could grow well on glucose under aerobic 
conditions but not under anaerobic conditions (Fig. 2a). Laboratory adaptive evolution by repeated transfers in glucose medium under anaerobic condition was not successful (Additional file 1: Fig. S1). With fructose or gluconate as the carbon source, however, SH5 $\Delta$ pgi could grow well under both aerobic and anaerobic conditions. Fructose enters the EMP pathway through the fructose6-phosphate (F6P) node, and gluconate enters the $\mathrm{PP} /$ ED pathways through the 6-phosphogluconate (6PG) node (Fig. 1). The growth capability of SH5 $\Delta$ pgi on either fructose or gluconate indicated that both the EMP pathway (after F6P) and the PP/ED pathway (after 6PG) functioned properly. In this light, we hypothesized that the lack of anaerobic growth of SH5 $5 p g i$ on glucose was caused by its inability to convert glucose-6-phosphate (G6P) to 6PG. We further posited that, when expressed from the chromosome, the activities of glucose-6-phosphate dehydrogenase (Zwf) and/or 6-phosphogluconolactonase (Pgl), which are the enzymes directing G6P towards the PP or ED pathway, are very low [26].
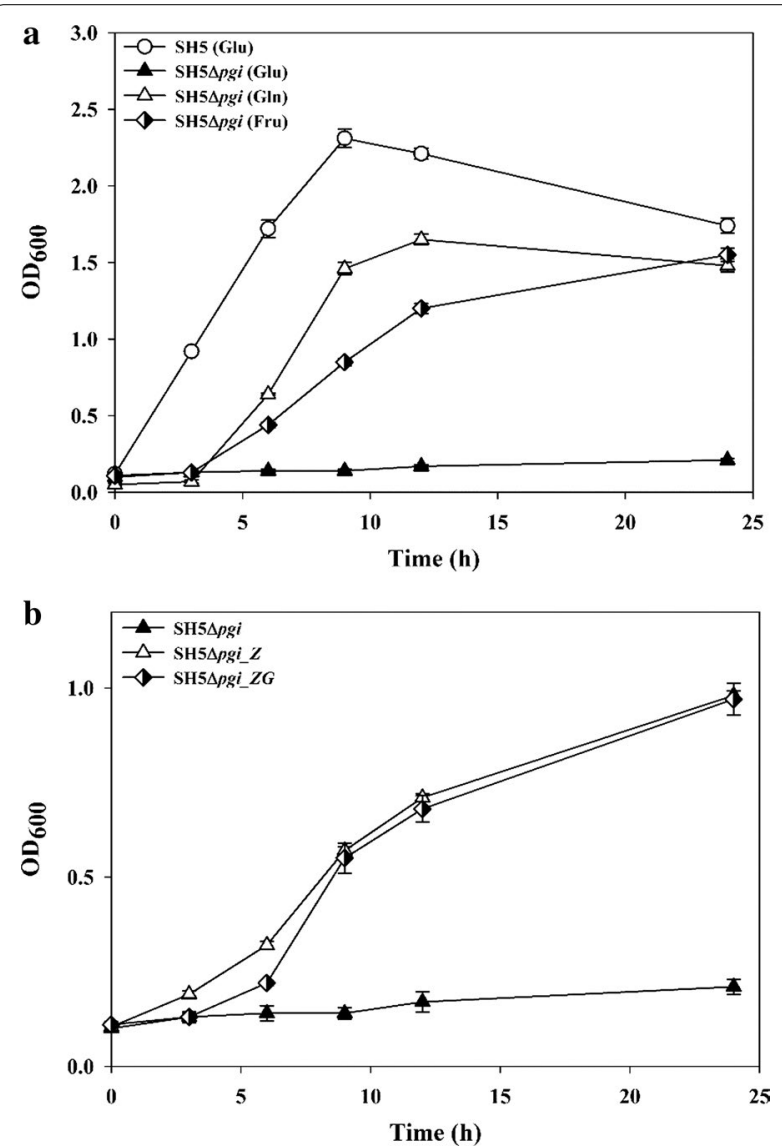

Fig. 2 Anaerobic growth of $\mathrm{SH} 5, \mathrm{SH} 5 \Delta$ pgi, and recombinant $\mathrm{SH} 5 \Delta$ pgi strains. a Growth of $\mathrm{SH} 5$ and $\mathrm{SH} 5 \Delta$ pgi on different carbon sources such as glucose (Glu), gluconate (Gln), and fructose (Fru). b Growth of SH5 $\triangle p g i$, SH5 $\triangle p g i \_$, and SH5 $\triangle p g i \_$ZG with glucose as carbon source. Refer to Table 1 for the genotype of each strain
To confirm our hypothesis, $z w f$ was homologously overexpressed by a multi-copy plasmid under the IPTG-inducible tac promoter. The resultant recombinant, SH5 $\Delta p g i \_Z$ could grow well on glucose under anaerobic conditions, though rather slowly compared with its parental strain SH5 (Fig. 2b). In order to determine if gnd expression can further improve cell growth, SH5 $\triangle p g i \_Z G$ was developed and tested. No difference from SH5 $\triangle p g i \_Z$ was observed. It was concluded that the incapacity of $E$. coli $\Delta p g i$ for anaerobic growth is rooted in the inefficient conversion of G6P to 6PG.

\section{Co-production of $\mathrm{H}_{2}$ and ethanol by E. coli $\Delta p g i$}

Co-production of $\mathrm{H}_{2}$ and ethanol was studied and compared among the strains of SH5, SH5 $\Delta p g i \_Z$, and SH5 $\triangle p g i \_Z G$ (Table 2). The strains were induced with $0.1 \mathrm{mM}$ IPTG, and the metabolites were analyzed at $\sim 24$ h of cultivation, when co-production was highest. SH5 $\Delta p g i \_Z$, as compared with SH5, showed improved production of all three major metabolites $\left(\mathrm{H}_{2}\right.$, ethanol, and acetate); this was attributed to the lower cell growth of SH5 $\Delta p g i \_Z$ (see Fig. 2) and the conversion of more glucose carbon to those metabolites. However, contrary to our expectation, the ratio of the production yield of ethanol to acetate did not increase in SH5 $\Delta p g i \_Z$ relative to SH5 (Table 2). In fact, if the PP pathway, which generates more $\mathrm{NAD}(\mathrm{P}) \mathrm{H}$, functions as the major glycolytic pathway in SH5 5 pgi_Z, more ethanol and less acetate should be produced. It was expected that the ED pathway, rather than the PP pathway, was activated by the overexpression of $z w f$, which generates the same amount of NAD $(\mathrm{P}) \mathrm{H}$ as the EMP pathway [13]. In comparison, when both $z w f$ and gnd were overexpressed (SH5 $\left.\triangle p g i \_Z G\right)$, ethanol production was greatly improved to $1.44 \mathrm{~mol} \mathrm{~mol}^{-1}$ with a concomitant acetate reduction to $0.22 \mathrm{~mol} \mathrm{~mol}^{-1}$. We concluded that whereas the cell growth of the $\Delta p g i$ mutant can be recovered by the overexpression of $z w f$ alone, the activation of the PP pathway

Table 2 Co-production by recombinant SH5 $\Delta$ pgi strains overexpressing Zwf and Gnd

\begin{tabular}{|c|c|c|c|c|}
\hline \multirow[t]{2}{*}{ Substrate } & \multirow[t]{2}{*}{ Strains } & \multicolumn{3}{|c|}{ Yields of metabolites $\left(\mathrm{mol} \mathrm{mol}^{-1}\right)$} \\
\hline & & $\mathrm{H}_{2}$ & Ethanol & Acetate \\
\hline \multirow[t]{3}{*}{ Glucose } & SH5 & $1.44 \pm 0.07$ & $0.79 \pm 0.02$ & $0.67 \pm 0.04$ \\
\hline & SH5 $\triangle p g i \_Z$ & $1.81 \pm 0.08$ & $0.90 \pm 0.02$ & $0.86 \pm 0.03$ \\
\hline & SH5 $\triangle p g i \_Z G$ & $1.68 \pm 0.06$ & $1.44 \pm 0.03$ & $0.22 \pm 0.02$ \\
\hline \multirow[t]{3}{*}{ Gluconate } & SH5 & $1.72 \pm 0.09$ & $0.58 \pm 0.01$ & $1.31 \pm 0.03$ \\
\hline & SH5 $\triangle p g i \_Z$ & $1.70 \pm 0.05$ & $0.68 \pm 0.01$ & $1.25 \pm 0.04$ \\
\hline & SH5 $\triangle p g i \_Z G$ & $1.69 \pm 0.07$ & $0.92 \pm 0.02$ & $0.85 \pm 0.02$ \\
\hline
\end{tabular}

Yields of metabolites were calculated from three individual experiments 
requires overexpression of both $z w f$ and gnd. Subsequent experiments with gluconate as a carbon source re-confirmed the importance of gnd overexpression for activation of the PP pathway (Table 2). Ethanol production from gluconate by SH5 $\Delta p g i \_Z$ was $0.68 \mathrm{~mol} \mathrm{~mol}^{-1}$, similar to that by $\mathrm{SH} 5$, while that by $\mathrm{SH} 5 \Delta$ pgi_ZG was $0.92 \mathrm{~mol} \mathrm{~mol}^{-1}$.

Although expression of $z w f$ and gnd greatly improved ethanol production while reducing acetate production, the theoretical maximum yield of ethanol production (1.67 mol mol $\mathrm{m}^{-1}$ glucose) was not achieved. To determine if ethanol production could be further improved, the expression levels of the two major enzymes, Zwf and Gnd, were varied by varying the IPTG concentration within the $0-0.3 \mathrm{mM}$ range during the cultivation of SH5 $\Delta p g i \_Z G$ (Fig. 3). With increasing IPTG concentration, production of Zwf and Gnd proteins (as analyzed by SDS-PAGE) and their enzymatic activities (from crude cell extract) increased almost linearly to $0.3 \mathrm{mM}$ IPTG. Accordingly, while acetate production decreased, ethanol production and the $\mathrm{CO}_{2} / \mathrm{H}_{2}$ ratio gradually increased. This indicated that when Gnd activity is enhanced, the flux through the PP pathway becomes more prominent than the ED pathway [16]. However, the ethanol yield increase, or the decrease in acetate production, almost halted at $0.1 \mathrm{mM}$ IPTG; moreover, even at the highest IPTG concentration tested in this study, $0.3 \mathrm{mM}$, about $0.2 \mathrm{~mol}$ acetate $\mathrm{mol}^{-1}$ glucose was produced.

\section{a}

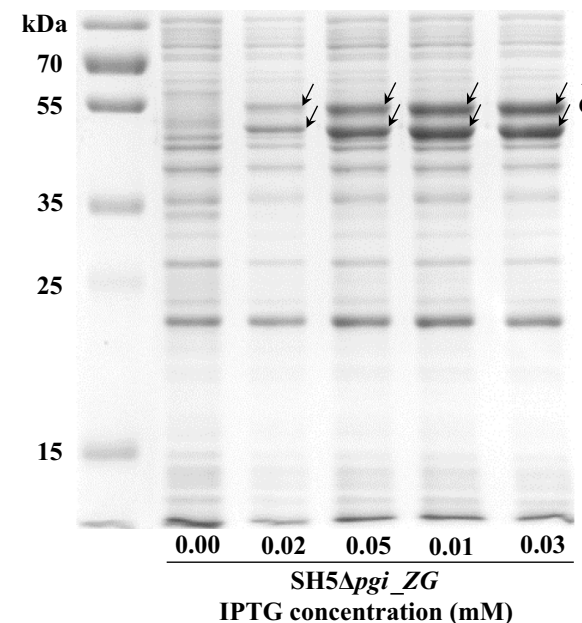

b

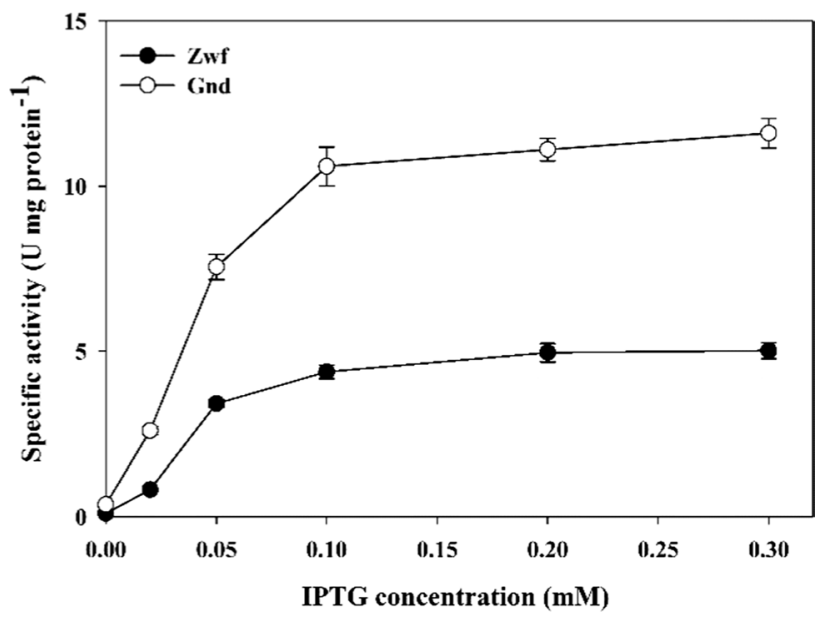

c

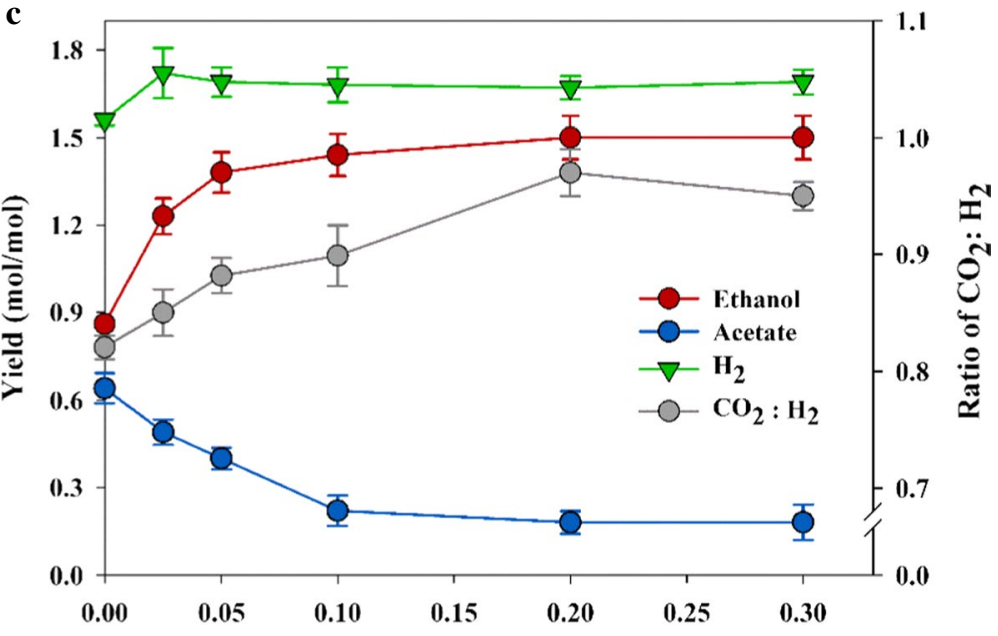

Concentration of IPTG ( $\mathrm{mM})$

Fig. 3 Effect of inducer concentration on co-production of $\mathrm{H}_{2}$ and ethanol by SH5 $\triangle$ pgi_ZG. a SDS-PAGE analysis of Zwf (55 kDa) and Gnd (51 kDa) in soluble fraction. $\mathbf{b}$ Enzyme activity of Zwf and Gnd of SH5 $\triangle p g i$ _ZG induced with different IPTG concentrations. $\mathbf{c}$ Metabolite yields and ratios of $\mathrm{CO}_{2}$ to $\mathrm{H}_{2}$ evolution of SH5 $\triangle$ pgi_ZG induced with $0,0.02,0.05,0.1,0.2$, and $0.3 \mathrm{mM}$ IPTG 
This observation suggests that achieving the theoretical maximum ethanol production level is impossible by simply controlling the expression level of the current Zwf and Gnd, because the carbon flux through the PP pathway cannot be sufficiently enhanced. Here, it seems that either the enzyme kinetics or the competition between Gnd and Edd determines the carbon distribution at the 6PG node, the amount of NAD $(\mathrm{P}) \mathrm{H}$ production, and/ or the ethanol production yield. In any case, we could achieve high co-production yields, $1.69 \mathrm{~mol} \mathrm{H}_{2} \mathrm{~mol}^{-1}$ glucose, and $1.50 \mathrm{~mol}$ ethanol $\mathrm{mol}^{-1}$ glucose, with SH5 5 pgi_ZG at 0.2 mM IPTG.

Next, RT-PCR analysis was performed to examine the changes in the gene expressions of the major glycolytic enzymes in SH5 $\Delta p g i$ Z and SH5 $5 p g i \_Z G$ (Table 3; Additional file 2: Appendix A). In both strains, transcription of $p g i$ was not observed, confirming the removal of $p g i$. The $z w f$ and/or gnd genes were highly expressed in SH5 $\triangle p g i \_Z$ and/or $\Delta p g i \_Z G$, and their levels increased when the cells were induced with higher IPTG concentrations. We noticed that the expressions of $p f k A$ and gapA increased as Zwf and Gnd were more expressed. We attributed these increased transcriptions to enhanced PP pathway flux, because the PP pathway is linked with the EMP pathway at F6P (pfkA) and glyceraldehyde-3-phosphate (G3P; gapA) nodes, and, with the ED pathway at G3P and pyruvate nodes [27]. Interestingly, transcription of $a d h E$ also significantly increased when the PP pathway was activated. In this regard, it has been reported that $a d h E$ transcription increases when the intracellular $\mathrm{NAD}(\mathrm{P}) \mathrm{H}$ level increases, and that this can enhance ethanol production [28]. Surprisingly in the present results, the expression level of $u d h A$, encoding NADH:NADPH transhydrogenase that converts

\begin{tabular}{|c|c|c|c|}
\hline Gene & $\begin{array}{l}\text { SH5 } \Delta p g i \_Z \\
(0.1 \mathrm{mM})\end{array}$ & $\begin{array}{l}\text { SH5 } \Delta p g i \_Z G \\
(0.1 \mathrm{mM})\end{array}$ & $\begin{array}{l}\text { SH5 } \Delta p g i \_Z G \\
(0.2 \mathrm{mM})\end{array}$ \\
\hline pgi & 0.00 & 0.00 & 0.00 \\
\hline$z w f$ & $2090.91 \pm 146.36$ & $2693.55 \pm 212.52$ & $8001.77 \pm 400.09$ \\
\hline gnd & $6.03 \pm 0.21$ & $2155.47 \pm 73.18$ & $6039.95 \pm 259.79$ \\
\hline$p f k A$ & $2.16 \pm 0.11$ & $3.59 \pm 0.06$ & $5.48 \pm 0.13$ \\
\hline$p f k B$ & $2.59 \pm 0.13$ & $1.29 \pm 0.03$ & $1.19 \pm 0.03$ \\
\hline gapA & $34.12 \pm 1.54$ & $44.01 \pm 0.96$ & $80.95 \pm 3.24$ \\
\hline edd & $1.41 \pm 0.02$ & $1.09 \pm 0.01$ & $0.87 \pm 0.01$ \\
\hline tktA & $12.20 \pm 0.24$ & $5.72 \pm 0.12$ & $7.28 \pm 0.16$ \\
\hline$p f l B$ & $42.99 \pm 1.38$ & $21.51 \pm 0.65$ & $37.04 \pm 0.74$ \\
\hline$f h / A$ & $0.38 \pm 0.01$ & $0.52 \pm 0.01$ & $0.43 \pm 0.01$ \\
\hline udhA & $0.45 \pm 0.01$ & $0.55 \pm 0.01$ & $0.28 \pm 0.01$ \\
\hline adhE & $4.51 \pm 0.05$ & $7.22 \pm 0.12$ & $13.76 \pm 0.47$ \\
\hline
\end{tabular}

The result was from three individual experiment repeats

$r p o D$ was used as the endogenous control and the transcriptional level of $r p o D$ was considered as 1
NADPH to NADH, did not change upon activation of the PP pathway. This raises the important question of whether NADPH is used directly or after being converted to NADH in the production of ethanol from acetyl-CoA (see "Limitations on PP pathway operation under anaerobic condition and expression of transhydrogenase").

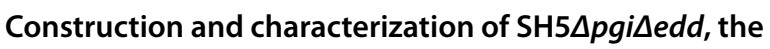 strain using PP pathway as sole glycolytic route}

The improved activity of Zwf and Gnd could not completely eliminate acetate production in SH5 5 pgi_ZG. Therefore, to make the PP pathway the sole glycolytic route, the ED pathway was blocked by disruption of the $e d d$ and eda genes from SH5 $\Delta p g i$. The resultant $\mathrm{SH} 5$ $\Delta$ pgisedd strain could grow on glucose under aerobic conditions but not at all under anaerobic conditions, even after overexpression of Zwf and Gnd (see Additional file 1: Fig. S2). This result, albeit disappointing, confirmed that the ED pathway is functioning in the SH5 $\Delta p g i \_Z G$ strain and metabolizing a portion of the glucose.

The inability of SH5 5 pgi $\Delta e d d \_Z G$ to grow on glucose under anaerobic condition is attributed to redox imbalance. According to the carbon and energy balance, when one glucose is fully metabolized through the PP pathway, $0.33 \mathrm{NADPH}$ is generated along with $1.67 \mathrm{H}_{2}$ and 1.67 ethanol [13] (Fig. 1b). The supplementation of yeast extract in the medium could have worsen the redox imbalance because it contains complex amino acids and some carbohydrates which can contribute to the regeneration of $\mathrm{NAD}(\mathrm{P}) \mathrm{H}$. If excess NADPH is accumulated, the PP pathway will be blocked along with termination of cell growth. To prove this hypothesis, two experiments were carried out. First, SH5 5 pgi $\Delta e d d \_Z G$ was grown on gluconate as the gluconate is more oxidized than glucose, and so no excess NADPH is accumulated. As expected, SH5 5 piisedd_ZG could grow on gluconate, though the rate is very slow (see Additional file 1: Fig. S2). In the course of that growth, ethanol and acetate were produced at yields of 0.79 and $0.84 \mathrm{~mol} \mathrm{~mol}^{-1}$, respectively, which makes the gluconate metabolism redox-balanced. In the second experiment, SH5 5 pgi $\Delta e d d \_Z G$ was grown on glucose but in the presence of nitrate (Additional file 1: Fig. S3). Nitrate can be used as an external electron acceptor and regenerate $\mathrm{NAD}(\mathrm{P})^{+}$under anaerobic conditions [29]. The results showed that the addition of nitrate recovered the growth of SH5 $\Delta$ pgi $\Delta$ edd even without the expression of Zwf and Gnd (Additional file 1: Fig. S3). The overexpression of Zwf and Gnd in the presence of nitrate increased the glucose consumption. However, neither $\mathrm{H}_{2}$ nor ethanol was produced; instead, acetate was the sole metabolite. In the presence of nitrate, E. coli oxidizes $\mathrm{NAD}(\mathrm{P}) \mathrm{H}$ to reduce nitrate and produce ATP. In summary, these two experiments strongly suggest that 
the redox imbalance and/or excessive NADPH generated by the PP pathway prevented SH5 $\Delta$ pgi $\Delta e d d \_Z G$ growth on glucose under anaerobic conditions.

It is possible to determine the minimal glucose flux to the ED pathway allowing for redox-balanced glucose metabolism using the carbon balance equation of PP and ED pathway (Fig. 1b) (see Additional file 1: Fig. S4). When NAD(P)H used for cell growth is ignored, the estimated minimal flux ratio of the ED pathway (i.e., ED flux/ sum of PP and ED fluxes) is 0.14 . If the minimal flux ratio of the ED pathway is below 0.14, the production and consumption of NAD(P)H cannot be matched by the production of ethanol and acetate. On the other hand, at any flux ratios above 0.14, combined production of acetate and ethanol makes the glucose metabolism redox-balanced and allows cells to grow.

\section{Limitations on PP pathway operation under anaerobic condition and expression of transhydrogenase}

According to the redox-balance analysis results plotted in Additional file 1: Fig. S4, the current SH5 $\Delta p g i \_Z G$ had a higher ED flux ( 0.32) than the ideal case (0.14). We speculate that despite high expression by the multi-copy plasmid, the enzymatic activities of Zwf and Gnd were low under the physiological conditions, and that this might be the reason why the flux ratio to the PP pathway did not increase above the $0.1 \mathrm{mM}$ IPTG shown in Fig. 3. It is known that Zwf and Gnd of E. coli are almost exclusively $\mathrm{NADP}^{+}$dependent and that their enzymatic activities are highly inhibited by NADPH $[24,30]$ (see Additional file 1: Table S2). Because the roles of Zwf and Gnd are so important, we cloned and characterized these enzymes from our own host E. coli BW25113 (Additional file 1: Fig. S5, Additional file 1: Table S2). The enzymes were expressed with a C-terminal His-tag and characterized after purification by Ni-NTA chromatography. Both of them were shown to be strictly dependent on $\mathrm{NADP}^{+}$, and no activity was observed with $\mathrm{NAD}^{+}$as the cofactor. The specific activities and $K_{\mathrm{m}}$ values of the purified Zwf and Gnd were similar to those that have been reported [30] (Additional file 1: Table S2). Additionally, we found that the two enzymes were inhibited by NADPH at similar levels $\left(K_{i}=\sim 40 \mu \mathrm{M}\right)$ but not at all by NADH.

The problem associated with high intracellular NADPH concentration and consequent inhibition on $\mathrm{Zwf}$ and Gnd can be solved in two ways: by (1) reducing the NADPH concentration and/or (2) employing less NADPH-sensitive enzymes. To explore the first approach, we overexpressed UdhA, the soluble transhydrogenase for the conversion of NADPH to NADH. E. coli strains have two transhydrogenases, one soluble ( $u d h A)$ and the other membrane bound (pntAB) [31]. Although both enzymes work reversibly, the former mainly catalyzes the reaction for the conversion of NADPH to NADH, and the latter, the reverse reaction [31]. To our disappointment, even after the overexpression of UdhA under a strong tac promoter, no improvement in ethanol production was observed in SH5 $\triangle p g i$ ZZG (Additional file 1: Fig. S6). Further, deletion of both $u d h A$ and pntA from SH5 $\Delta p g i \_Z G$ did not affect cell growth or metabolite formation: SH5 $\Delta p g i \Delta u d h A \Delta p n t A \_Z G$ grew similar to SH5 $\triangle p g i \_Z G$ and produced similar amounts of $\mathrm{H}_{2}$, ethanol, and acetate (Additional file 1: Fig. S6). These results are puzzling, because they indicate that the roles of the two transhydrogenases are negligible in glucose metabolism, and also that ethanol production in SH5 $\triangle p g i$ ZG and other derived strains might be NADPH dependent. In any case, it is clear that overexpression of transhydrogenases cannot be the solution to the problem that necessitates reduction of intracellular NADPH levels and/or enhancement of carbon flux through the PP pathway.

\section{Use of heterologous zwf and gnd}

In another attempt to improve the carbon flux to the PP pathway, we overexpressed heterologous Zwf and Gnd which are less inhibited by NADPH. If such enzymes can use $\mathrm{NAD}^{+}$as the cofactor, the reduction of the intracellular NADPH level would be also expected. For the Zwf and Gnd reported in the literature and enzyme databases, cofactor specificity, activity, and NADPH-dependent inhibition were analyzed and compared (Additional file 1: Table S2). The $\mathrm{Zwf}$ from Zymomonas mobilis $\left(\mathrm{Z}_{\mathrm{Z}}\right)$ had an approximately sevenfold higher activity than that of $E$. coli $\left(\mathrm{Z}_{\mathrm{E}}\right.$; note that the subscript ' $\mathrm{E}$ ' was added to avoid confusion) [32]. Furthermore, it could use both $\mathrm{NAD}^{+}\left(K_{\mathrm{m}}\right.$, $210 \mu \mathrm{M})$ and $\mathrm{NADP}^{+}\left(K_{\mathrm{m}}, 40 \mu \mathrm{M}\right)$, though preferring the latter more. The $\mathrm{Zwf}$ from Leuconostoc mesenteroides $\left(\mathrm{Z}_{\mathrm{L}}\right)$ also showed a sevenfold higher activity than that of $Z_{E}$, and could use $\mathrm{NAD}^{+}$as a cofactor, having a higher affinity $\left(K_{\mathrm{m}}\right.$, $106 \mu \mathrm{M})$ than $\mathrm{Z}_{\mathrm{Z}}[33,34]$. Interestingly, the Gnd from Gluconobacter oxydans $\left(\mathrm{G}_{\mathrm{G}}\right)$ showed a higher affinity to $\mathrm{NAD}^{+}$ $\left(K_{\mathrm{m}}, 64 \mu \mathrm{M}\right)$ than to $\mathrm{NADP}^{+}\left(K_{\mathrm{m}}, 440 \mu \mathrm{M}\right)$, whereas Gnd from Corynebacterium glutamicum $\left(\mathrm{G}_{\mathrm{C}}\right)$ showed a fivefold higher activity than that of $E$. coli $\left(\mathrm{G}_{\mathrm{E}}\right)$, though its use of $\mathrm{NAD}^{+}$as a cofactor is not known $[24,35]$.

Next, different recombinant plasmids were constructed for the expression of heterologous $\mathrm{Zwf}\left(\mathrm{Z}_{\mathrm{E}}, \mathrm{Z}_{\mathrm{L}}\right.$, $\left.\mathrm{Z}_{\mathrm{Z}}\right)$ and $\mathrm{Gnd}\left(\mathrm{G}_{\mathrm{E}}, \mathrm{G}_{\mathrm{G}}, \mathrm{G}_{\mathrm{C}}\right)$ in various combinations and then introduced to SH5 $\Delta p g i$ to generate eight recombinant strains (Table 4). These recombinant SH5 $\Delta p g i$ strains were studied for the growth and production of $\mathrm{H}_{2}$ and ethanol with glucose as the carbon source. Except for SH5 $5 p g i Z_{E} G_{C}$ and SH5 $5 p g i Z_{E} G_{G}$, the other (six) strains grew well and produced $\mathrm{H}_{2}$ similar to that of SH5 $\triangle$ pgi_ $Z_{E} G_{E}$ at $1.6 \pm 0.1 \mathrm{~mol} \mathrm{~mol}{ }^{-1}$ glucose. Those six recombinant strains also generated similar or higher amounts of ethanol than SH5 $\triangle p g i$ ZZG; among them, the 
Table 4 Co-production by recombinant SH5 $\Delta p g i$

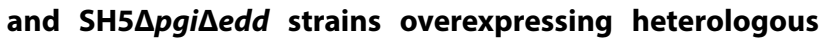
Zwf and Gnd

\begin{tabular}{|c|c|c|c|}
\hline \multirow[t]{2}{*}{ Strains } & \multirow[t]{2}{*}{ Relative growth rate } & \multicolumn{2}{|c|}{$\begin{array}{l}\text { Yield of metabolites } \\
\left(\mathrm{mol} \mathrm{mol}^{-1}\right)\end{array}$} \\
\hline & & Ethanol & Acetate \\
\hline$\Delta p g i \_Z G$ & +++ & $1.44 \pm 0.07$ & $0.22 \pm 0.03$ \\
\hline$\Delta p g i \_Z_{L} G_{E}$ & ++ & $1.48 \pm 0.04$ & $0.25 \pm 0.02$ \\
\hline$\Delta p g i \_Z_{Z} G_{E}$ & +++ & $1.49 \pm 0.06$ & $0.32 \pm 0.01$ \\
\hline$\Delta p g i \_Z_{E} G_{C}$ & + & $1.35 \pm 0.05$ & $0.37 \pm 0.01$ \\
\hline$\Delta p g i \_Z_{L} G_{C}$ & +++ & $1.46 \pm 0.06$ & $0.26 \pm 0.01$ \\
\hline$\Delta p g i \_Z_{Z} G_{C}$ & +++ & $1.32 \pm 0.07$ & $0.49 \pm 0.01$ \\
\hline$\Delta p g i \_Z_{E} G_{G}$ & + & $1.52 \pm 0.09$ & $0.22 \pm 0.02$ \\
\hline$\Delta p g i \_Z_{L} G_{G}$ & ++ & $1.62 \pm 0.06$ & $0.06 \pm 0.01$ \\
\hline$\Delta p g i Z_{Z} G_{G}$ & ++ & $1.46 \pm 0.07$ & $0.35 \pm 0.01$ \\
\hline$\Delta$ pgisedd_Z $Z_{L} G_{G}^{a}$ & ++ & $1.01 \pm 0.03$ & $0.40 \pm 0.01$ \\
\hline
\end{tabular}

The result was from three individual experiment repeats

${ }^{a} \Delta p g i \Delta e d d_{-} \mathrm{Z}_{\mathrm{L}} \mathrm{G}_{\mathrm{G}}$ was grown on gluconate

SH5 5 pgi_ $Z_{L} G_{G}$ strain, which expresses Zwf of L. mesenteroides and Gnd of G. oxydans, showed the highest ethanol production yield at $1.62 \mathrm{~mol} \mathrm{~mol}^{-1}$ glucose as well as the lowest acetate production yield at $\sim 0.06 \mathrm{~mol} \mathrm{~mol}^{-1}$ glucose. It was considered that the high activity and dualcofactor specificity of $\mathrm{Z}_{\mathrm{L}}$ along with the NAD ${ }^{+}$dependence of $G_{G}$ were the main reasons for the improved performance of SH5 $\Delta p g i Z_{L} G_{G}$. The flux ratio of the ED pathway in this strain, moreover, was estimated to be close to the thermodynamically allowed lowest level, 0.14 (see Additional file 1: Fig. S4).

The same plasmid expressing both Zwf of L. mesenteroides and Gnd of G. oxydans (pLmZ-GoG) was introduced to SH5 5 pgisedd to determine if these highly efficient Zwf and Gnd can enable its anaerobic growth. As expected, the resulting recombinant $\mathrm{SH} 5 \Delta$ pgised $d \_Z_{L} G_{G}$ could not grow anaerobically with glucose as the carbon source. This confirmed that redox imbalance does not permit use of the PP pathway as the sole glycolytic route of glucose metabolism under anaerobic conditions. The same SH5 5 pgisedd_ $Z_{L} G_{G}$ strain was also cultured on gluconate as the carbon source. In fact, it could grow much better than SH5 (Additional file 1: Fig. S2), producing more ethanol $\left(1.01 \mathrm{vs.} 0.79 \mathrm{~mol} \mathrm{~mol}^{-1}\right)$ and less acetate $(0.40 \mathrm{vs}$. $\left.0.85 \mathrm{~mol} \mathrm{~mol}^{-1}\right)$. This result confirmed once again that the highly efficient $\mathrm{Zwf}\left(\mathrm{Z}_{\mathrm{L}}\right)$ and $\mathrm{Gnd}\left(\mathrm{G}_{\mathrm{G}}\right)$ can effectively activate the PP pathway.

The $\Delta p f k A$ strains could grow well after long adaptation to anaerobic growth [14] and produced good amounts of $\mathrm{H}_{2}$ and ethanol $\left(\sim 1.7 \mathrm{~mol} \mathrm{H}_{2} \mathrm{~mol}^{-1}\right.$ and $\sim 1.40 \mathrm{~mol}$ ethanol mol ${ }^{-1}$ ) when Zwf and Gnd, the key enzymes of the PP pathway, were overexpressed. However, due to the active expression of $p f k B$ which encodes for the isozyme of PfkA, up to $30 \%$ of glucose was metabolized through the EMP pathway in the $\triangle p f k A$ strains and substantial amount of acetate was produced $\left(\sim 0.15 \mathrm{~mol} \mathrm{~mol}^{-1}\right)$. On the other hand, the $\Delta p g i$ strains led us to understand the metabolic hurdles in achieving theoretical maximum yield. In addition, the usage of efficient $\mathrm{Zwf}$ and Gnd enzymes in the $\Delta p g i$ strains led us to successfully achieve the theoretical maximum yield of $\mathrm{H}_{2}$ and ethanol ( 1.6 $\mathrm{mol} \mathrm{mol}^{-1}$ each).

\section{Conclusions}

The E. colispgi mutant could grow on glucose under anaerobic conditions when Zwf was overexpressed, but when both Zwf and Gnd were overexpressed, diversion of the carbon flux through the PP pathway and efficient coproduction of $\mathrm{H}_{2}$ and ethanol were possible. Operation of the PP pathway as the sole glycolytic route for glucose under anaerobic conditions, however, was not possible, due to the redox imbalance. When the EMP pathway was blocked by pgi deletion, there existed, for the ED pathway, a critical flux ratio (0.14) above which cell growth was possible. The flux distribution between the PP and ED pathways at the 6-phosphogluconate node, and the co-production yield of $\mathrm{H}_{2}$ and ethanol, were determined by the characteristics of Zwf and Gnd. When $z w f$ from $L$. mesenteroides and gnd from G. oxydans, both of which use $\mathrm{NAD}^{+}$and NADP ${ }^{+}$as cofactors and are less inhibited by NADPH, were employed, the best co-production yield of $\mathrm{H}_{2}$ and ethanol (1.74 $\mathrm{mol} \mathrm{H}_{2} \mathrm{~mol}^{-1}$ glucose; $1.62 \mathrm{~mol}$ ethanol mol${ }^{-1}$ glucose), close to the theoretical maximum values $\left(1.67 \mathrm{~mol} \mathrm{~mol}^{-1}\right.$ glucose for each), resulted. Activation of the PP pathway, as presented in this work, will be found to be useful for developing efficient biocatalysts for other biofuels and biochemicals that require additional reducing power and need to be produced under anaerobic conditions.

\section{Additional files}

Additional file 1: Table S1. Details of Zwf and Gnd used in this study. Table S2. Kinetic properties of Zwf and Gnd used in this study. Figure S1. Adaptive evolution for anaerobic growth of $\mathrm{SH} 5 \Delta p g i$ with glucose as substrate. Figure S2. Anaerobic growth of recombinant SH5 $\Delta p g i \Delta e d d$ strains on glucose (Glu) and gluconate (Gln). Refer to Table 1 for the genotype of each strain. Figure S3. Growth and acetate production yield of SH5 5 pgi $\Delta e d d$ and SH5 $\triangle$ pgi $\Delta$ edd_ZG on glucose in the presence of nitrate. Figure S4. Theoretical prediction of relation between dependence on ED pathway and ethanol and acetate production. Redox-imbalanced region denotes the production of excess NADPH than pyruvate. Figure S5. SDSPAGE analyses of Zwf ( $55 \mathrm{kDa}$ ) and $\mathrm{Gnd}(51 \mathrm{kDa}$ ) in soluble fraction SH5 pDK7_zwf (Lane 1) and SH5_pDK7_gnd (Lane 2) and purified Zwf (Lane 3) and Gnd (Lane 4) by Ni-NTA chromatography. Figure S6. Growth and metabolites production yield of SH5 $\triangle p$ pi_ZGU and SH5 $\triangle p g i \Delta u d h A \triangle p n t A_{-}$ ZG on glucose.

Additional file 2: Appendix A. Raw data of RT-PCR analysis. 


\section{Abbreviations}

$\mathrm{CO}_{2}$ : carbon dioxide; ED: Entner-Doudoroff; EMP: Embden-Meyerhof-Parnas; $\mathrm{H}_{2}$ : hydrogen; IPTG: isopropyl- $\beta$-D-thiogalactopyranoside; $\mathrm{OD}_{600}$ : optical density; Pgi: phosphoglucose isomerase; PP: pentose-phosphate.

\section{Authors' contributions}

BSS, ES, and SP designed the research. BSS and ES performed the experiments and wrote the manuscript. The manuscript was revised and critical comments were provided by SP. All authors read and approved the final manuscript.

\section{Acknowledgements}

Not applicable.

\section{Competing interests}

The authors declare that they have no competing interests.

\section{Funding}

This research was supported by C1 Gas Refinery Program through the National Research Foundation of Korea (NRF) funded by the Ministry of Science, ICT \& Future Planning (NRF-2016M3D3A1A01913248). This work was also supported by the Advanced Biomass R\&D Center (ABC) of Global Frontier Project funded by the Ministry of Science, ICT \& Future Planning (ABC-2011-0031361). The authors are grateful also to the BK21 Plus program at Pusan National University.

Received: 17 November 2016 Accepted: 22 March 2017

Published online: 29 March 2017

\section{References}

1. Rittmann S, Herwig C. A comprehensive and quantitative review of dark fermentative biohydrogen production. Microb Cell Fact. 2012;11:115-33.

2. Hallenbeck PC. Fermentative hydrogen production: principles, progress, and prognosis. Int J Hydrogen Energy. 2009;34:7379-89.

3. Abo-Hashesh M, Wang R, Hallenbeck PC. Metabolic engineering in dark fermentative hydrogen production; theory and practice. Bioresour Technol. 2011;102:8414-22.

4. Oh YK, Raj SM, Jung GY, Park S. Current status of the metabolic engineering of microorganisms for biohydrogen production. Bioresour Technol. 2011;102:8357-67.

5. Wang $\mathrm{S}$, Huang $\mathrm{H}, \mathrm{Moll}$ J, Thauer RK. NADP+ ${ }^{+}$reduction with reduced ferredoxin and $\mathrm{NADP}^{+}$reduction with $\mathrm{NADH}$ are coupled via an electron-bifurcating enzyme complex in Clostridium kluyveri. J Bacteriol. 2010;192:5115-23.

6. Zeidan AA, Van Niel EW. A quantitative analysis of hydrogen production efficiency of the extreme thermophile Caldicellulosiruptor owensensis $\mathrm{OL}^{\top}$. Int J Hydrogen Energy. 2010;35:1128-37.

7. Soboh B, Linder D, Hedderich R. A multisusbunit membrane-bound [NiFe] hydrogenase and an NADH-dependent Fe-only hydrogenase in the fermenting bacterium Thermoanaerobacter tengcongensis. Microbiology. 2004;150:2451-63.

8. Veit A, Akhtar MK, Mizutani T, Jones PR. Constructing and testing the thermodynamic limits of synthetic $\mathrm{NAD}(\mathrm{P}) \mathrm{H}$ : $\mathrm{H}_{2}$ pathways. Microb Biotechnol. 2008;1:382-94.

9. Verhaart MR, Bielen AA, van der Oost J, Stams AJ, Kengen SW. Hydrogen production by hyperthermophilic and extremely thermophilic bacteria and archaea: mechanisms for reductant disposal. Environ Technol. 2010;31:993-1003.

10. Foglia D, Wukovits W, Friedl A, de Vrije T, Claassen P. Fermentative hydrogen production: influence of application of mesophilic and thermophilic bacteria on mass and energy balances. Chem Eng Trans. 2011;25:815-20.

11. Hema R, Agrawal P. Production of clean fuel from waste biomass using combined dark and photofermentation. IOSR J Comput Eng. 2012;1:39-47.

12. Peixoto G, Pantoja-Filho JLR, Agnelli JAB, Barboza M, Zaiat M. Hydrogen and methane production, energy recovery, and organic matter removal from effluents in a two-stage fermentative process. Appl Biochem Biotechnol. 2012;168:651-71.
13. Seol E, Ainala SK, Sundara Sekar B, Park S. Metabolic engineering of Escherichia coli strains for co-production of hydrogen and ethanol from glucose. Int J Hydrogen Energy. 2014;39:19323-30.

14. Sundara Sekar B, Seol E, Raj SM, Park S. Co-production of hydrogen and ethanol by pfkA-deficient Escherichia coli with activated pentose-phosphate pathway: reduction of pyruvate accumulation. Biotechnol Biofuels. 2016;9:95-106.

15. Yazdani SS, Gonzalez R. Engineering Escherichia coli for the efficient conversion of glycerol to ethanol and co-products. Metab Eng. 2008;10:340-51.

16. Seol E, Sundara Sekar B, Raj SM, Park S. Co-production of hydrogen and ethanol from glucose by modification of glycolytic pathways in Escherichia coli-from Embden-Meyerhof-Parnas pathway to pentose phosphate pathway. Biotechnol J. 2015;11:249-56.

17. Chemler JA, Fowler ZL, McHugh KP, Koffas MA. Improving NADPH availability for natural product biosynthesis in Escherichia coli by metabolic engineering. Metab Eng. 2010;12:96-104.

18. Siedler S, Bringer S, Polen T, Bott M. NADPH-dependent reductive biotransformation with Escherichia coli and its pfkA deletion mutant: influence on global gene expression and role of oxygen supply. Biotechnol Bioeng. 2014;111:2067-75.

19. Kim S, Seol E, Oh YK, Wang GY, Park S. Hydrogen production and metabolic flux analysis of metabolically engineered Escherichia coli strains. Int J Hydrogen Energy. 2009;34:7417-27.

20. Ko Y, Ashok S, Seol E, Ainala SK, Park S. Deletion of putative oxidoreductases from Klebsiella pneumoniae J2B could reduce 1,3-propanediol during the production of 3-hydroxypropionic acid from glycerol. Biotechnol Bioprocess Eng. 2015;20:834-43.

21. Datsenko KA, Wanner BL. One-step inactivation of chromosomal genes in Escherichia coli K-12 using PCR products. Proc Natl Acad Sci. 2000;97:6640-5.

22. Kleiner D, Paul W, Merrick MJ. Construction of multicopy expression vec tors for regulated over-production of proteins in Klebsiella pneumoniae and other enteric bacteria. J Gen Microbiol. 1988;134:1779-84.

23. Zhou S, Ainala SK, Seol E, Nguyen TT, Park S. Inducible gene expression system by 3-hydroxypropionic acid. Biotechnol Biofuels. 2015;8:169-76.

24. Moritz B, Striegel K, de Graaf AA, Sahm H. Kinetic properties of the glucose-6-phosphate and 6-phosphogluconate dehydrogenases from Corynebacterium glutamicum and their application for predicting pentose phosphate pathway flux in vivo. Eur J Biochem. 2000;267:3442-52.

25. Kruger NJ. The Bradford method for protein quantitation. In: Walker JM, editor. The protein protocols handbook, Chapter 4. Totowa, NJ: Humana Press Inc.; 2009. p. 17-24.

26. Duffieux F, Van Roy J, Michels PA, Opperdoes FR. Molecular characterization of the first two enzymes of the pentose-phosphate pathway of Trypanosoma brucei. Glucose-6-phosphate dehydrogenase and 6-phosphogluconolactonase. J Biol Chem. 2000;275:27559-65.

27. Stryer L, Berg JM, Tymoczko JL. The calvin cycle and pentose phosphate pathway. In: Biochemistry, Chapter 20, 7th edn. W. H. Freeman and Company New York; 1995. p. 589-614.

28. Leonardo MR, Dailly Y, Clark DP. Role of $\mathrm{NAD}^{+}$in regulating the adhE gene of Escherichia coli. J Bacteriol. 1996;178:6013-8.

29. Ashok S, Raj SM, Ko Y, Sankaranarayanan M, Zhou S, Kumar V, et al. Effect of puuC overexpression and nitrate addition on glycerol metabolism and anaerobic 3-hydroxypropionic acid production in recombinant Klebsiella pneumoniae $\Delta g l p K \Delta d h a T$. Metab Eng. 2013;15:10-24.

30. Olavarría K, Valdés D, Cabrera R. The cofactor preference of glucose6-phosphate dehydrogenase from Escherichia coli-modeling the physiological production of reduced cofactors. FEBS J. 2012;279:2296-309.

31. Sauer U, Canonaco F, Heri S, Perrenoud A, Fischer E. The soluble and membrane-bound transhydrogenases UdhA and PntAB have divergent functions in NADPH metabolism of Escherichia coli. J Biol Chem. 2004:279:6613-9

32. Scopes RK, Testolin V, Stoter A, Griffiths-Smith K, Algar EM. Simultaneous purification and characterization of glucokinase, fructokinase and glucose-6-phosphate dehydrogenase from Zymomonas mobilis. Biochem J. 1985:228(3):627-34

33. Levy HR, Vought VE, Yin X, Adams MJ. Identification of an arginine residue in the dual coenzyme-specific glucose-6-phosphate dehydrogenase from Leuconostoc mesenteroides that plays a key role in binding NADP+ but not NAD ${ }^{+}$. Arch Biochem Biophys. 1996:326:145-51. 
34. Vought V, Ciccone T, Davino MH, Fairbairn L, Lin Y, Cosgrove MS, et al. Delineation of the roles of amino acids involved in the catalytic functions of Leuconostoc mesenteroides glucose 6-phosphate dehydrogenase. Biochemistry. 2000;39:15012-21.
35. Tonouchi N, Sugiyama M, Yokozeki K. Coenzyme specificity of enzymes in the oxidative pentose phosphate pathway of Gluconobacter oxydans. Biosci Biotechnol Biochem. 2003;67:2648-51.

\section{Submit your next manuscript to BioMed Central} and we will help you at every step:

- We accept pre-submission inquiries

- Our selector tool helps you to find the most relevant journal

- We provide round the clock customer support

- Convenient online submission

- Thorough peer review

- Inclusion in PubMed and all major indexing services

- Maximum visibility for your research

Submit your manuscript at www.biomedcentral.com/submit
() Biomed Central 